water, carrying with it any oil or rubber that may have been associated with the phosphorus, as well as the detritus from the inactivating reaction. The skin is left almost entirely clean and unstained.

Anaesthetized rats were treated, after dehairing, with a few drops of white phosphorus dissolved in $\mathrm{CS}_{2}$, and, after allowing the solvent to evaporate, the layer of phosphorus was inactivated by application of the above copper preparations. There was considerable difficulty in applying the $1 \%$ copper sulphate aqueous solution, since the rat's skin and the phosphorus layer are alike difficult to wet with aqueous solutions. The copper-glycerol mixture was better in this respect but reacted slowly compared with the oil-soluble copper preparation. Minute pieces of phosphorus applied to the skin were rendered inactive by the oil-soluble copper solution and disintegrated, while the copper sulphate solution and the copper-glycerol mixture rendered them inactive but left them entire. Here again the $1 \%$ copper sulphate reacted more quickly than the copper-glycerol once it had been brought into intimate contact with the phosphorus.

Phosphorus applied to the skin either alone or in solution in $\mathrm{CS}_{2}$ appears to have no immediately deleterious action. Its danger resides wholely in its liability to ignite and cause burns which do not easily heal. This point was shown not only by animal experiments but by application to the human skin. Phosphorus allowed to ignite on the skin (after evaporation of the $\mathrm{CS}_{2}$ in which the phosphorus was dissolved) is immediately extinguished by the oil-soluble copper preparation, and inactivation of the phosphorus begins almost at once.

\section{Proposed Procedure for dealing with} Phosphorus on the Skin

1. Extinguish burning areas (immersion in water or wet fire-blankets).

2. Apply oil-soluble copper compound to areas contaminated with phosphorus (swabbing, pouring over areas, in some cases even immersing affected parts: manner of application will suggest itself according to circumstances. In general it will be best to deal with the affected parts piecemeal while keeping the waiting parts wet with water).

3. After well-established and obvious inactivation of the phosphorus (in general, in from a few seconds to one or two minutes), wash the treated area with tepid water and swab off the contaminating material.

4. Treat area with excess sodium bicarbonate, working up into a paste with water.

5. Treatment of the burn itself will naturally depend on circumstances, but if all the phosphorus is inactivated and removed and all acidity is neutralized, accepted methods on the lines of antisepsis and mild tanning should be applicable. The location of the burn, its depth, and the amount of tissue destroyed must all be considered in the treatment. General rules for all cases are misleading.

\section{Summary}

The phosphorus-inactivating properties of $1 \%$ aqueous copper sulphate, the copper sulphate-glycerol-starch composition of Godding and Notton, and a new composition containing copper in an oil-soluble form made from copper oleate, Turkeyred oil (sulphonated castor-oil), trichloroethylene, and surgical spirit have been compared. The last is shown to be the most effective way of inactivating phosphorus, especially when associated with oil, solvents, or rubber. A procedure is suggested for dealing with cases contaminated with material from self-igniting bombs containing phosphorus, oil, solvents, and rubber.

N.B.-It must be pointed out that the treatment proposed is for phosphorus on the skin. The high content of trichloroethylene precludes use of the composition for such internal injuries as were

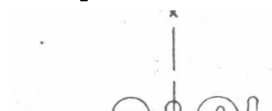

recently described by Blaxland (1942), in which elemental phosphorus was diffusely implanted in the tissues.

\section{REFERENCES}

Bird and Diggs (1914). J. Amer. chem. Soc., 36, 1382.

Blaxland, A.J. (1942) British Medical Journal, 664

Godding, E. W., and Notton, H. E. F. (1942). Ibid., 1, 433.

Jones, A. T. (1942). Ibid., 2, 244. Ministry of Home Security (1942). Phosphorus and Other Bombs now being
used by the Enemy, August 1.

used by the Enemy, August 1.
Straub, W. (1903). Z. anorg. Chem., 35, 460.

\section{MODIFICATION FOR $\mathrm{CO}_{2}$ ABSORPTION WITH THE FIELD-PATTERN BOYLE'S APPARATUS \\ BY}

J. MONTGOMERIE, M.B., D.A.

Major, R.A.M.C.; Anaesthetist to a General Hospital

With the object of effecting economy of gases I have devised a modification of the field-pattern Boyle's apparatus by which carbon dioxide absorption may be used. This has proved to be very satisfactory in practice. The essential additions are a flowmeter for "basal " oxygen and a soda-lime canister. A description of these impro-

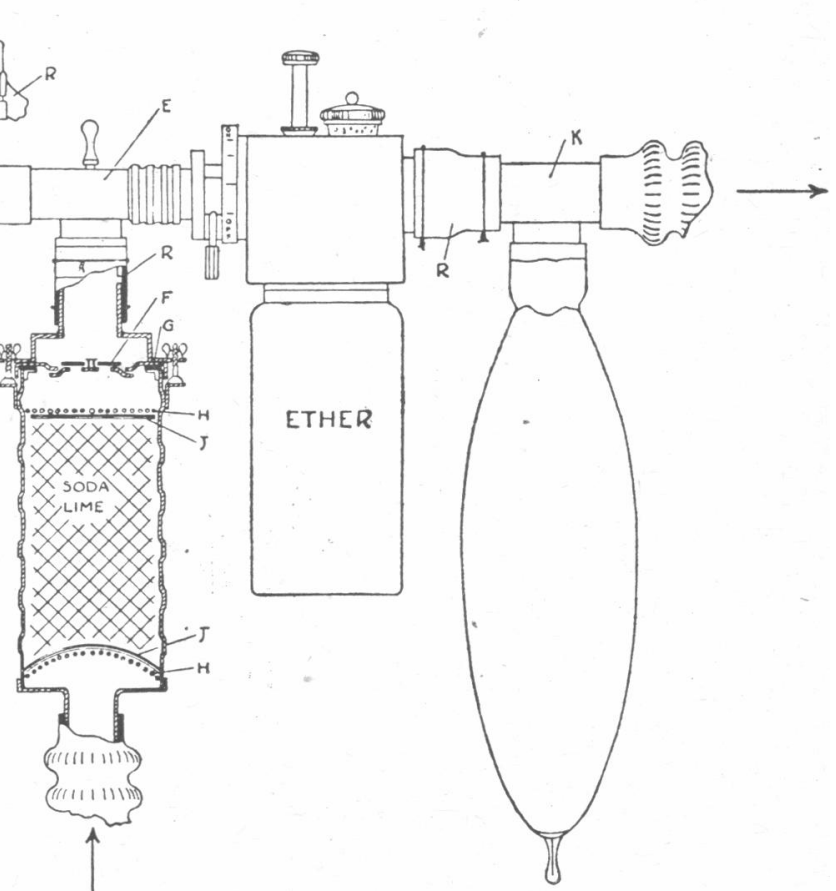

Fig. 1.-Front view; $\mathrm{CO}_{2}$ absorber in section. A, Plug. c, Scale. E. Magili's bag-mount. $R$, Rubber connexions. (Other reference letters E. Magills bag-mount. $R$, Rubber connexions.
explained in text. Scale of drawings, $1 / 4$ size )

visations is given in the hope that it may be of use to other anaesthetists.

\title{
The Flowmeter
}

The flowmeter (Figs. 1, 4, and 5) was designed to fit inside the sight-feed bottle, and is of the water-depression type. Its design was restricted by the limited space available. The oxygen cylinder is connected to the middle sight-feed tube, $\mathrm{CO}_{2}$ not being used. Oxygen thus passes to the top of the bottle by way of the metal sleeve and tube (D), and escapes through a glass capillary (M). T indicates a connexion to the glass depression tube (B): The scale was cut from zinc-alloy sheet, and is wired to the normal oxygen sight-feed tube. Calibration was carried out by timing the displacement of water from a large measuring bottle. Preliminary experiments determined the proper size of capillary tube to obtain the desired range -200 to $650 \mathrm{c.cm}$. a minute.

Nitrous oxide is run in through the normal sight-feed tube. 


\section{The Carbon Dioxide Absorber}

The canister was improvised from a training-model Service respirator container (Fig. 1). The bottom (inspiratory valve end) was unsoldered and fitted as a lid by attaching lugs to receive bolts fixed to the body. There are four of these, only two showing in the section. A rubber washer (G) ensures a gas-tight joint. A flat metal cylinder and a short length of 1 -in. tube soldered over the hole in the lid enables a connecting tube to be attached. All the contents of the container were

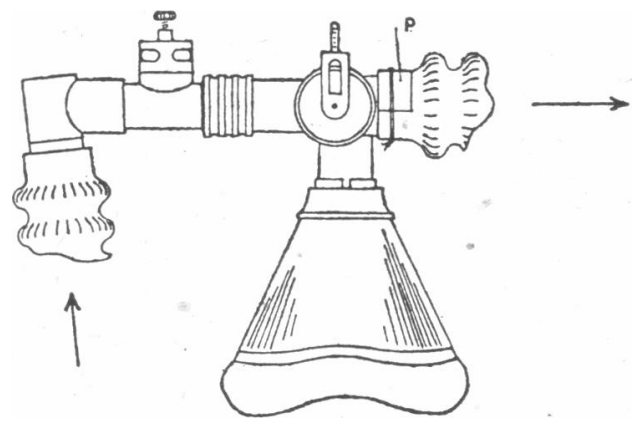

Fig. 2.-Arrangement of face-piece fittings. P, Tin strip over slot in stopcock.

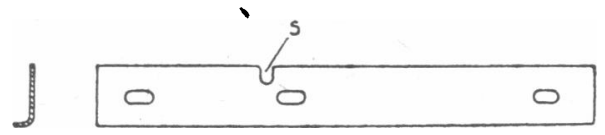

FIG. 3.-Detail of extension bracket. s, Slot for handle of bagmount valve when closed.

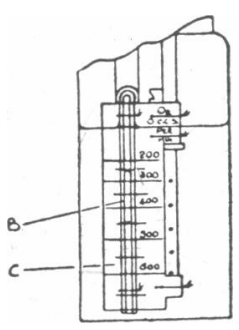

FIG. 4.-Side view of flowmeter, showing scale.

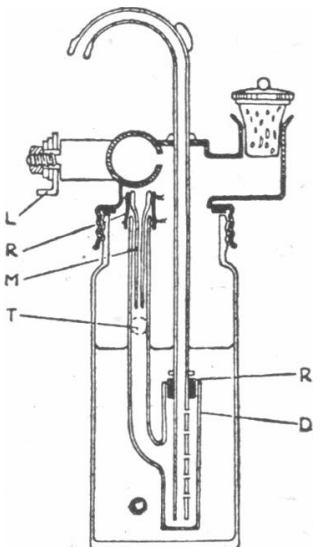

Fig. 5.-Section of flowmeter. removed and two of the pieces of metal gauze (H) with lint pads (J) used to retain the soda-lime, $1 \mathrm{lb}$. of which can be accommodated. The unfilled space of about 1 in. at the upper end is important to avoid " channelling."

\section{Arrangement of Apparatus}

The arrangement shown in Fig. 1 works on the "circle" principle and permits vaporization of ether by the expired gases. The absorber is connected to the Magill bag-mount which is fitted between the ether bottle and flowmeter. The latter is supported by an extension bracket cut from brass sheet (Fig. 3, and L, Fig. 5). The bag is mounted on an improvised T-tube (K). One-way gas flow is attained by incorporating the stopcock from a nitrous oxide-air apparatus, with the cap over the expiratory valve removed, in the face-piece fittings (Fig. 2). The inspiratory valve of the respirator (P) is fitted, as shown in Fig. 1, to prevent back-flow of gases into the absorber when it is not in circuit. This assembly results in some expiratory resistance, due to the by-pass control on the ether bottle. With quiet breathing the pressure at the mask is not excessive, being between 2 and $3 \mathrm{~mm}$. $\mathrm{Hg}$; but an appreciable increase occurs with deep breathing and if the gases are bubbled through the ether.

Two alternative arrangements may be used. In the first, the flowmeter and ether bottle are left in their usual positions and the absorber is fitted between the ether bottle and the rebreathing-bag. In the second, the canister is fitted near the face-piece and "to-and-fro" absorption is used. Both alternatives overcome the expiratory resistance, but ether vaporization is dependent on the small "basal" flow of gases only.

Additional corrugated tube is improvised from the respirator connecting tube. All rubber connexions are secured by binding with wire. The materials used are easily obtainable in the field, and constructional work can be carried out by the nearest workshop unit. It will be noted that the Boyle apparatus is not altered structurally.

\section{Notes on Technique}

(1) Adequate sedative premedication is desirable.

(2) A full anaesthetic dose of pentothal sodium, followed by nitrous oxide-oxygen with this apparatus, has been very successful.

(3) When an intravenous anaesthetic is not used, induction is most satisfactorily carried out by the " semi-closed" method, $\mathrm{CO}_{2}$ absorption being started when surgical anaesthesia is well established.

(4) Owing to the diffusibility of nitrous oxide it is seldom possible to discontinue its flow completely, and about $500 \mathrm{c.cm}$. a minute is required for maintenance.

(5) The composition of the gas mixture tends to change slowly during the course of the anaesthesia. As with nitrous oxide-oxygen a fine balance is struck between anoxia and the patient becoming "lighter," this is important, and is best overcome by periodically emptying the bag and refilling with the appropriate mixture.

\section{A NEW CIRCLE-TYPE CARBON DIOXIDE ABSORBER \\ BY}

WILLIAM W. MUSHIN, M.B., B.S., D.A.

Honorary Anaesthetist, Seamen's Hospital, Greenwich, and Central London Throat, Nose, and Ear Hospital; Anaesthetist, Royal Dental Hospital; Anaesthetist, E.M.S.

With the collaboration of Messrs. Coxeter and Son, Ltd., who initiated this endeavour, a circle-type absorber with certain unique features, and in which anaesthetic requirements have been combined with mechanical efficiency, has been produced: The aims of its design and the way these aims have been achieved are as follows.

The machine was specifically intended to fit the standard Boyle machine that has been distributed widely in the E.M.S. It slides on two runners fixed to the table frame, and can be pushed under the top shelf when not in use. Minimum restriction to breathing was achieved by using wide-bore gas channels throughout, and making the patient's respirations take a path with as few changes of direction as possible. Large control drums are used and special glanding arrangements provided to eliminate leakage. In the ether vaporizer, wicks, which to be effective need several thicknesses and which soon cause restriction, have been eliminated. The moving parts of the reservoir bag are carefully balanced on ball bearings, and move with the slightest respiratory effort. The measured restriction of the circuit is $2 \mathrm{~mm} . \mathrm{H}_{2} \mathrm{O}$ with the ether and sodalime " off " and $4 \mathrm{~mm}$. $\mathrm{H}_{2} \mathrm{O}$ with both " on."

High-efficiency absorption of $\mathrm{CO}_{2}$ was achieved by departing from the orthodox type of circuit and employing one in which both inspirations and expirations pass through the soda-lime, thus combining the absorptive efficiency of the "to-and-fro" type with the practical advantages of the "circle-type" absorber.

The type of ether vaporizer normally used in an absorber circuit has a wick to give sufficient surface of contact of the 